\title{
Optimum concentration of dissolved oxygen for the survival of virulent Treponema pallidum under conditions of low oxidation-reduction potential
}

\author{
S: GRAVES AND T. BILLINGTON \\ From the Department of Microbiology, Monash University Medical School, Alfred Hospital, Prahran, \\ Australia
}

SUMMARY A maintenance medium with a low oxidation-reduction (redox) potential, when gently bubbled with $5 \%$ oxygen in nitrogen or with air for various periods of time, gave a range of dissolved oxygen concentrations between 1.6 and $5.8 \mu \mathrm{g} / \mathrm{l}$. Virulent Treponema pallidum (Nichols strain) inoculated into these media were assayed 24 and 48 hours later for motility and virulence and were compared with samples taken at zero time. Virulent $T$. pallidum survived best in the presence of $2.4 \mu \mathrm{g} / 1$ dissolved oxygen over a 48 -hour period, which corresponded to a gaseous mixture of $3 \%$ oxygen in nitrogen. Higher concentrations of oxygen did not give significantly different results from anaerobic conditions over this period. Thus, until it can be grown in vitro, $T$. pallidum would appear to be a microaerophilic bacterium.

\section{Introduction}

During this century attempts to grow virulent Treponema pallidum (the causative agent of syphilis) in vitro have been unsuccessful despite claims to the contrary (Willcox and Guthe, 1966). Growth of avirulent $T$. pallidum from a virulent inoculum has recently been reported (Sandok et al., 1976, 1978). Since the availability of large numbers of $T$. pallidum which are relatively free from host-cell contaminants is probably a prerequisite for the development of a vaccine against syphilis, attempts to grow this bacterium in vitro are important steps in reducing the incidence of this disease.

For many years $T$. pallidum has been considered a strict anaerobe with a low oxidation-reduction (redox) optimum (Metzger and Smogor, 1966). Only in reduced media could the organism maintain its viability, as measured by rabbit virulence. Recently this opinion has been challenged. Freshly isolated $T$. pallidum utilises oxygen at a rate equivalent to that of aerobic organisms (Cox and Barber, 1974), and the presence of a cytochrome system (Lysko and

Address for reprints: Dr S Graves, Department of Microbiology, Monash University Medical School, Alfred Hospital, Prahran, Victoria 3181, Australia

Received for publication 27 April 1979
Cox, 1977), suggests that this organism may respire aerobically. Glucose oxidation, pyruvate degradation, and protein synthesis were stimulated under aerobic conditions (Baseman et al., 1976). Norris et al. (1978), using a reduced culture medium, found that virulent $T$. pallidum survived better under $3 \%$ oxygen than under either aerobic or anaerobic conditions, indicating that the bacterium is microaerophilic.

The importance of oxygen for the survival and metabolism of $T$. pallidum has also been shown in tissue culture systems where the addition of superoxide dismutase to infected cell monolayers prolonged the virulence of $T$. pallidum (Fitzgerald $e t$ al., 1975). With certain cell lines and reduced culture medium an atmosphere of $3 \%$ oxygen maintained $T$. pallidum without loss of virulence for six days (Fitzgerald et al., 1977) and $2 \cdot 5 \%$ oxygen enabled a surface acid mucopolysaccharide to be synthesised as a result of the cell-treponeme interaction (Fitzgerald et al., 1978). Fieldsteel et al. (1977) established an oxygen gradient in tissue culture and found that $T$. pallidum survived best in a region neither fully aerobic nor anaerobic, indicating the importance of microaerobiosis for the survival of $T$. pallidum. Kiraly and Horvath (1976) used low oxygen conditions (7 mm $\mathrm{Hg}$ partial pressure) and found that $T$. pallidum survived well, but in their work 
survival was poorer with, rather than without, a tissue culture system.

In our study, an optimum dissolved oxygen concentration of $2.4 \mu \mathrm{g} / \mathrm{l}$ (corresponding to a gaseous mixture of $3 \% \mathrm{O}_{2}$ in $\mathrm{N}_{2}$ ) was required for $T$. pallidum to retain its virulence.

\section{Materials and methods}

\section{PROPAGATION OF T. PALLIDUM}

The bacterium was grown in the testes of serologically negative rabbits by inoculating approximately $5 \times 10^{7}$ viable $T$. pallidum per testis and harvesting it 11 days later, at which time orchitis has developed. Rabbits (of various breeds) were housed at $18^{\circ} \mathrm{C}$ to permit satisfactory growth of the $T$. pallidum. After the rabbit had been killed with intravenous sodium pentobarbitone, the testes were removed aseptically and minced in successive $5-\mathrm{ml}$ samples of medium (see below) under aerobic conditions. This eluted the $T$. pallidum from the tissue, yielding about $10^{7}$ organisms $/ \mathrm{ml}$. The suspension was used without purification and $0.5 \mathrm{ml}$ was inoculated into $10-\mathrm{ml}$ tubes of medium to give a final concentration of $T$. pallidum of about $5 \times 10^{5} / \mathrm{ml}$. This concentration varied from experiment to experiment depending on the concentration of treponemes in the rabbit testes. The $1 / 20$ dilution of the inoculum into experimental medium meant that the treponemes were only exposed to air, albeit in a reduced medium, for about 30 minutes.

\section{T. PALLIDUM IN VITRO}

After inoculation of the medium with $T$. pallidum under a stream of sterile, oxygen-free nitrogen the tubes were tightly sealed with butyl rubber stoppers (Bellco Glass Inc., Vineland, New Jersey), placed in anaerobic jars to prevent extraneous oxygen entering the medium, and incubated at $35^{\circ} \mathrm{C}$.

\section{PREPARATION OF MEDIUM}

The medium of Graves et al. (1975) was modified and made in two parts (A and B), which were combined immediately before inoculation with $T$. pallidum. The compositions of medium A and B are shown in Table 1. Medium A (without buffered bicarbonate solution or reducing agents) was prereduced by autoclaving at $121^{\circ} \mathrm{C}$ for eight minutes with slow exhaust. Immediately after removal from the autoclave the medium was continuously flushed with oxygen-free nitrogen until cool; the latter was obtained by passing nitrogen through a hot copper column before use. When the medium was cool, buffered bicarbonate solution and reducing agents (as powders) were added by gently stirring. The pH
Table 1 Composition of $T$. pallidum maintenance medium

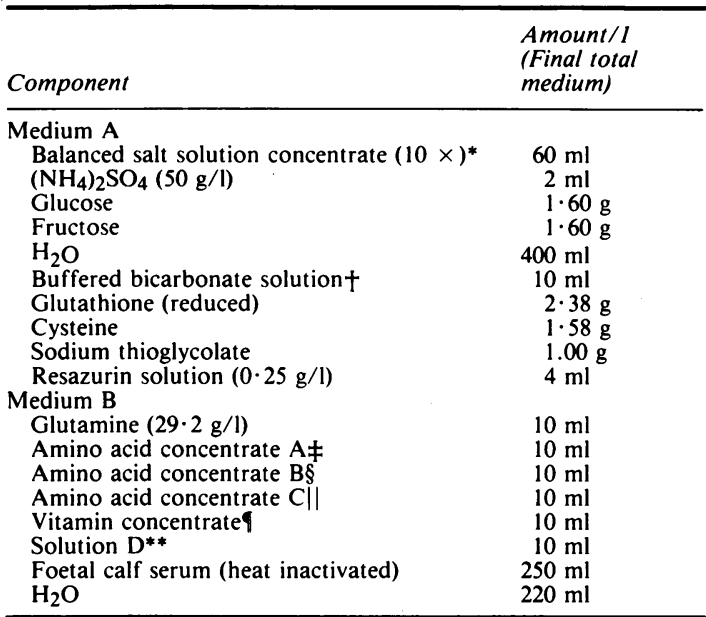

* $\mathrm{NaCl}(40 \mathrm{~g} / \mathrm{l}), \mathrm{KCl}(4 \mathrm{~g} / \mathrm{l}), \mathrm{CaCl}_{2}(1.4 \mathrm{~g} / \mathrm{l}), \mathrm{Na}_{2} \mathrm{HPO}_{4}(0.6 \mathrm{~g} / \mathrm{l})$, $\mathrm{KH}_{2} \mathrm{PO}_{4}(0.6 \mathrm{~g} / \mathrm{l}), \mathrm{MgSO}_{4} .7 \mathrm{H}_{2} \mathrm{O}(2 \mathrm{~g} / \mathrm{l})$

$+\mathrm{NaHCO}_{3}(50 \mathrm{~g} / \mathrm{l}), \mathrm{K}_{2} \mathrm{HPO}_{4}(40 \mathrm{~g} / \mathrm{l})$ and $\mathrm{KH}_{2} \mathrm{PO}_{4}(8 \mathrm{~g} / \mathrm{l})$

†Composition per $10 \mathrm{ml}$ : arginine $\mathrm{HCl}, 105 \mathrm{mg}$; histidine $\mathrm{HCl} \mathrm{H} \mathrm{H}_{2} \mathrm{O}$, $31 \mathrm{mg}$; isoleucine, $52 \mathrm{mg}$; leucine, $52 \mathrm{mg}$; lysine $\mathrm{HCl} 58 \mathrm{mg}$; methionine, $15 \mathrm{mg}$; phenylalanine, $32 \mathrm{mg}$; threonine, $48 \mathrm{mg}$; tryptophan, $10 \mathrm{mg}$; and valine, $46 \mathrm{mg}$

§Composition per $10 \mathrm{ml}$ : cystine, $24 \mathrm{mg}$ and tyrosine, $36 \mathrm{mg}$

||Composition per $10 \mathrm{ml}$ : alanine, $8.9 \mathrm{mg}$ : asparagine $\mathrm{H}_{2} \mathrm{O}, 15 \mathrm{mg}$; aspartic acid, 13.3 mg; glutamic acid, $14.7 \mathrm{mg}$; proline, $11.5 \mathrm{mg}$; serine, $10.5 \mathrm{mg}$; and glycine, $7.5 \mathrm{mg}$

Composition per $10 \mathrm{ml}$ : choline chloride, $1 \mathrm{mg}$; folic acid, $1 \mathrm{mg}$; 1 -inositol, $2 \mathrm{mg}$; nicotinamide, $1 \mathrm{mg}$; calcium pantothanate, $1 \mathrm{mg}$; pyridoxal $\mathrm{HCl}, 1 \mathrm{mg}$; riboflavin, $0.1 \mathrm{mg}$; and thiamine $\mathrm{HCl}, 1 \mathrm{mg}$ **Composition per $10 \mathrm{ml}$ : sodium pyruvate, $250 \mathrm{mg}$; adenine, $5 \mathrm{mg}$; cocarboxylase, $3 \mathrm{mg}$; coenzyme A, $50 \mu \mathrm{g}$; isobutyric acid, $10 \mathrm{mg}$; $\alpha$-lipoic acid, $5 \mathrm{mg}$; p-amino benzoic acid, $5 \mathrm{mg}$; biotin, $50 \mu \mathrm{g}$; nicotinic acid, $500 \mu \mathrm{g}$; pyridoxine $\mathrm{HCl}, 2 \cdot 5 \mathrm{mg}$; pyridoxamine $\mathrm{HCl}$, $5 \mathrm{mg}$; putrescine $2 \mathrm{HCl}, 10 \mathrm{mg}$; and cyanocobalamin, $50 \mu \mathrm{g}$

of the solution was adjusted to 8.6 with $10 \mathrm{~mol} / \mathrm{l}$ $\mathrm{NaOH}$. The medium was maintained under a stream of nitrogen until it was added to nitrogen-flushed, anaerobic tubes (Bellco Glass Inc.) using a pipette preflushed with nitrogen $(4 \cdot 7 \mathrm{ml} /$ tube). The tubes were tightly sealed with butyl rubber stoppers and autoclaved in a press at $121^{\circ} \mathrm{C}$ for 15 minutes using fast exhaust. Medium A was never prepared earlier than one day before use. After medium $A$ had been cooled, medium $B$ was added to the tubes of medium A under sterile, oxygen-free nitrogen. To make $10 \mathrm{ml}$ of complete medium, $5 \cdot 3 \mathrm{ml}$ of medium $B$ was added to $4.7 \mathrm{ml}$ of medium A. All components of medium B were previously sterilised by filtration. The final pH was $7 \cdot 2-7 \cdot 4$.

\section{OXYGEN BUBBLING INTO MEDIUM}

Cylinders of $5 \%$ oxygen in nitrogen (Commonwealth Industrial Gases, Melbourne, Australia) or of air were used to add oxygen to the medium. When medium A had been prepared, and immediately 
before it was added to the nitrogen-flushed anaerobic tubes, it was bubbled with the appropriate gas mixture for the predetermined time. For example, $5 \% \mathrm{O}_{2} \times 15$ minutes means 15 minutes' bubbling with $5 \% \mathrm{O}$, for every $10 \mathrm{ml}$ of medium being prepared, that is, 150 minutes for $100 \mathrm{ml}$ final medium. The bubbling rate was approximately 2 bubbles per second from a 21-mm Pasteur pipette (orifice diameter approximately $1 \mathrm{~mm}$ ). After bubbling, medium $A$ was dispensed in $4 \cdot 7-\mathrm{ml}$ volumes into nitrogen-flushed anaerobic tubes and sterilised by autoclaving in a press; medium B was then added as before.

\section{MEASUREMENT OF OXYGEN IN MEDIUM}

An oxygen meter (Model LR-30, Titron Australia, Melbourne), fitted with a Clark-type oxygen electrode modified to allow measurement in static solutions, was used. The meter gave readings in 'part per million' $(\mu \mathrm{g} / \mathrm{l})$ dissolved oxygen in water. The electrode was calibrated at $22^{\circ} \mathrm{C}$ with air (being the same as air-saturated water at $\left.22^{\circ} \mathrm{C}\right), 5 \% \mathrm{O}_{2}, 3 \% \mathrm{O}_{2}$, and $1 \% \mathrm{O}_{2}$ in nitrogen and $100 \%$ nitrogen (oxygenfree). The exact oxygen concentration in the gas mixtures was determined by the suppliers (Commonwealth Industrial Gases, Melbourne) and was accurate to $0 \cdot 1 \%$. The relationship between oxygen-meter readings $(\mu \mathrm{g} / \mathrm{l})$ and $\mathrm{O}_{2}$ concentration in the gas was linear (Figure); this was the standard

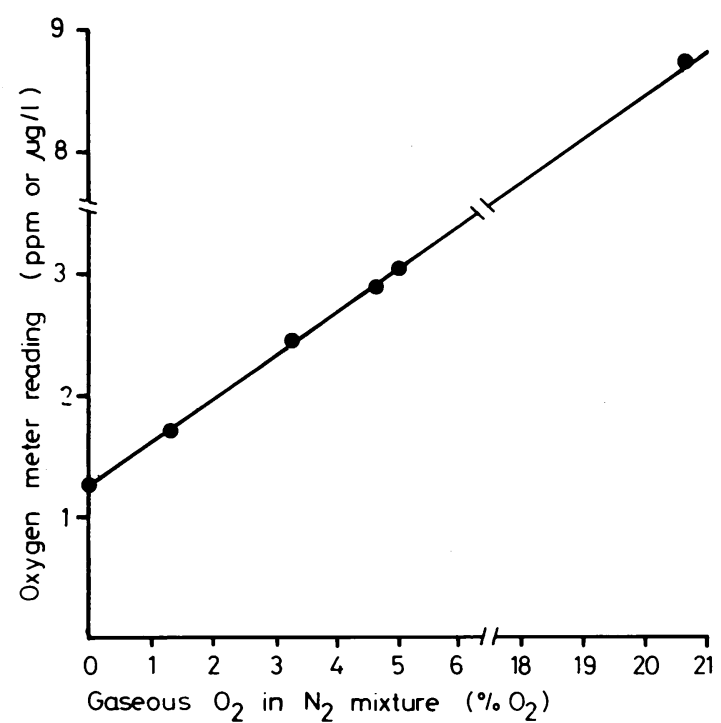

Figure Relationships between oxygen meter reading and concentration of oxygen in the gaseous $\mathrm{O}_{2}-\mathrm{N}_{2}$ mixture. This standard curve was used to determine the oxygen concentrations in culture media as equivalent gaseous oxygen concentrations. curve from which all subsequent $\mathrm{O}_{2}$ concentrations in media were determined. We appreciated that the calibration curve, based on dissolved oxygen concentration in water, was not strictly applicable to the culture medium. Chemical determinations of dissolved oxygen concentrations in the culture media were not done. However the method used enabled the most appropriate gaseous $\mathrm{O}_{2}-\mathrm{N}_{2}$ mixture for optimum retention of $T$. pallidum virulence in the culture medium to be determined.

Dissolved oxygen measurements on triplicate tubes were performed at daily intervals. Fresh tubes were used for readings at each time interval because insertion of the oxygen electrode biologically contaminated the medium. The electrode was inserted into the bottom of the 10-ml column of medium and stable readings were obtained within one to two minutes. Exposing the medium to air for this short time did not affect the oxygen reading, as confirmed by flushing control tubes with nitrogen while taking oxygen readings.

\section{MEASUREMENT OF REDOX POTENTIAL IN THE MEDIUM}

A platinum calomel combination redox electrode (Model 96-78, Orion, Cambridge, Massachusetts) was connected to an Orion model 701A 'digital ionalyser' and inserted directly into the medium for five minutes. Measurements were made at approximately $22^{\circ} \mathrm{C}$ and $\mathrm{pH} 7 \cdot 3$. The redox potential was read directly from the millivolt scale of the meter. The efficacy of the electrode was confirmed with a standard redox system of potassium ferricyanide and potassium ferrocyanide as recommended by the manufacturer. The readings obtained, being based on a calomel reference electrode, are designated Ecal; to convert them to Eh values, approximately $241 \mathrm{mV}$ must be added to the reading (Jacob, 1970) - that is, $-276 \mathrm{mV}$ (Ecal) is equivalent to $-35 \mathrm{mV}$ (Eh).

DETERMINATION OF $T$. PALLIDUM VIRULENCE Samples $(0.6 \mathrm{ml})$ of culture medium were taken immediately after inoculation with $T$. pallidum and at 24, and 48 hours thereafter. Each sample was mixed with $0.6 \mathrm{ml}$ of sterile deoxygenated $20 \%$ glycerol in saline and stored at $-70^{\circ} \mathrm{C}$ until all samples were available. Samples were thawed immediately before inoculation into the rabbit. The backs of male rabbits were shaved and marked into a $10-\mathrm{cm} \times 10-\mathrm{cm}$ grid, which was subdivided into 16 equal areas. Into each site $0.1 \mathrm{ml}$ of culture was injected intradermally. For each time sample, quadruplicate samples were injected into each rabbit $(4 \times 0 \mathrm{~h} ; 4 \times 24 \mathrm{~h} ; 4 \times 48 \mathrm{~h})$. Rabbits were kept shaved and cool $\left(18^{\circ} \mathrm{C}\right)$ and examined daily for 
development of lesions as determined by the detection of induration at the site of inoculation, which subsequently developed into a typical syphilitic lesion. Some of these lesions were abraded and shown to contain treponemes. The time the lesions took to develop for the 24-hour and 48-hour samples was compared with that for the zero time samples. Testing all samples from one experiment on the same rabbit overcame the problem of variability between rabbits in their susceptibility to $T$. pallidum.

DETERMINATION OF $T$. PALLIDUM MOTILITY Darkfield microscopy was used to examine $100 \mathrm{~T}$. pallidum chosen at random in a drop of culture medium on a microscope slide. Each bacterium was scored as motile or non-motile and the percentage motility of the culture determined. Only actively motile $T$. pallidum were considered motile-that is, those with snapping, spinning, or flexing motions. For each experiment motility determinations were carried out in triplicate from three identical tubes of media.

Statistical comparisons were made by Student's $t$ test.

\section{Results}

The anaerobic medium (Table 1) used for the maintenance of $T$. pallidum could be made partially aerobic by bubbling $5 \%$ oxygen in nitrogen or air into it for various periods of time. Maximum oxygenation obtained in this series of experiments was $5 \cdot 8 \mu \mathrm{g} / \mathrm{l}$, equivalent to an atmosphere of $12 \cdot 6 \%$ oxygen (Table 2 ) with a series of lower values down to $1.6 \mu \mathrm{g} / \mathrm{l}$ (equivalent to an atmosphere of $0.7 \%$ oxygen), the anaerobic medium.

Redox potentials of the anaerobic medium were not affected by bubbling the medium with $5 \%$ oxygen in nitrogen (data not shown), but bubbling with air did cause the redox potential to become more positive (Table 3). Bubbling the medium with air for 60 minutes produced the highest redox
Table 2 Measurement of dissolved oxygen concentration in medium* following bubbling with $5 \%$ oxygen in nitrogen or air for specified periods

\begin{tabular}{llll}
\hline & \multicolumn{3}{l}{$\begin{array}{l}\text { Dissolved oxygen concentration } \\
\text { in } \mu \mathrm{g} / \mathrm{l}\left(\% \mathrm{O}_{2}\right)\end{array}$} \\
\cline { 2 - 4 } $\begin{array}{l}\text { Method of } \\
\text { oxygen addition }\end{array}$ & Day 0 & Day l & Day 2† \\
\hline No oxygenation & $1 \cdot 6(0 \cdot 7)$ & $1 \cdot 6(0 \cdot 7)$ & $1 \cdot 6(0 \cdot 7)$ \\
$5 \% 0 \mathrm{O}_{2}$ in $\mathrm{N}_{2} \times 5 \mathrm{~min}$ & $1 \cdot 8(1 \cdot 3)$ & $1 \cdot 8(1 \cdot 3)$ & $1 \cdot 7(1 \cdot 0)$ \\
$5 \% 0 \mathrm{O}_{2}$ in $\mathrm{N}_{2} \times 15 \mathrm{~min}$ & $2 \cdot 4(3 \cdot 0)$ & $2 \cdot 2(2 \cdot 4)$ & $2 \cdot 1(2 \cdot 1)$ \\
$\mathrm{Air} \times 30 \mathrm{~min}$ & $2 \cdot 95(4 \cdot 7)$ & $2 \cdot 6(3 \cdot 6)$ & $2 \cdot 4(3 \cdot 0)$ \\
Air $\times 40 \mathrm{~min}$ & $3 \cdot 8(7 \cdot 3)$ & $3 \cdot 6(6 \cdot 5)$ & $3 \cdot 4(5 \cdot 9)$ \\
Air $\times 50 \mathrm{~min}$ & $5 \cdot 0(10 \cdot 4)$ & $3 \cdot 6(6 \cdot 5)$ & $2 \cdot 0(1 \cdot 9)$ \\
Air $\times 60 \mathrm{~min}$ & $5 \cdot 8(12 \cdot 6)$ & $4 \cdot 2(8 \cdot 2)$ & $2 \cdot 1(2 \cdot 1)$ \\
\hline
\end{tabular}

* Mean of five independent samples. Measurements made immediately after inoculation of medium with $T$. pallidum (day 0 ) and on days 1 and 2

tThe fall in oxygen concentration over the two-day period is presumably due primarily to removal of the added free oxygen by reducing agents in the medium, as very little would be due to treponemal metabolism

Table 3 Oxidation reduction (redox) potential $(\mathrm{mV})$ of medium after bubbling with air for specified periods

\begin{tabular}{llll}
\hline \multirow{2}{*}{$\begin{array}{l}\text { Method of } \\
\text { oxygen addition }\end{array}$} & \multicolumn{3}{l}{ Redox potential $(\mathrm{mV})^{*}$} \\
\cline { 2 - 4 } & Day 0 & Day l & Day 2 \\
\hline No oxygenation & -276 & -272 & -254 \\
Air $\times 30 \mathrm{~min}$ & -271 & -271 & -265 \\
Air $\times 40 \mathrm{~min}$ & -263 & -263 & -261 \\
Air $\times 50 \mathrm{~min}$ & -259 & -258 & -227 \\
Air $\times 60 \mathrm{~min}$ & -243 & -240 & -229 \\
\hline
\end{tabular}

* Mean of four independent samples. Measurements made immediately after inoculation of medium with $T$. pallidum (day 0 ) and on days 1 and 2

potentials, but even so the medium was still 'reduced' relative to a calomel reference electrode.

The oxygenation of the medium did not have a marked effect on the reduction in percentage motility of the $T$. pallidum culture (Table 4); by day 2 the more oxygenated cultures were slightly less motile than the anaerobic controls.

Using the intradermal inoculation test on the shaved back of the rabbit, a trend was observed when the cultures were tested for the presence of virulent $T$. pallidum. In anaerobic medium the latent period of infection was shortened by only 0.2 day over the first 24 hours. The only oxygenated media to

Table 4 Determination of motility of Treponema pallidum cultures (\%) maintained in medium bubbled with 5\% oxygen in nitrogen or air for specified periods

\begin{tabular}{|c|c|c|c|c|c|}
\hline \multirow[b]{2}{*}{ Method of oxygen addition } & \multicolumn{3}{|c|}{ Time of motility estimation * } & \multirow{2}{*}{$\begin{array}{l}\text { \% decrease } \\
\text { (day } 0 \text { to day I) }\end{array}$} & \multirow{2}{*}{$\begin{array}{l}\% \text { decrease } \\
\text { (day } 0 \text { to day 2) }\end{array}$} \\
\hline & Day 0 & Day 1 & Day 2 & & \\
\hline $\begin{array}{l}\text { No oxygenation } \\
5 \% \mathrm{O}_{2} \times 5 \mathrm{~min} \\
5 \% \mathrm{O}_{2} \times 15 \mathrm{~min} \\
\mathrm{Air} \times 30 \mathrm{~min} \\
\mathrm{Air} \times 40 \mathrm{~min} \\
\text { Air } \times 60 \mathrm{~min}\end{array}$ & $\begin{array}{l}100 \\
100 \\
100 \\
100 \\
100 \\
100\end{array}$ & $\begin{array}{l}94 \\
96 \\
91 \\
88 \\
91 \\
85\end{array}$ & $\begin{array}{l}80 \\
91 \\
77 \\
67 \\
73 \\
62\end{array}$ & $\begin{array}{r}6 \\
4 \\
9 \\
12 \\
9 \\
15\end{array}$ & $\begin{array}{r}20 \\
9 \\
23 \\
33 \\
27 \\
38\end{array}$ \\
\hline
\end{tabular}

* Mean of three samples from each of three identical tubes of media 
alter significantly the difference in the latent period was after being bubbled with $5 \% \mathrm{O}_{2}$ for 15 minutes (Table 5). After bubbling with $5 \% \mathrm{O}_{2}$ for 15 minutes (that is, $2.4 \mu \mathrm{g} / 1$ dissolved $\mathrm{O}_{2}$ concentration equivalent to a $3 \%$ oxygen atmosphere; Table 2 ), the difference in latent period was 1.4 days (Table 5).

Table 5 Latent period of syphilitic lesions after inoculation of $T$. pallidum into the shaved backs of rabbits*

\begin{tabular}{|c|c|c|c|}
\hline \multirow{2}{*}{$\begin{array}{l}\text { Method of } \\
\text { oxvgen addition }\end{array}$} & \multicolumn{2}{|c|}{$\begin{array}{l}\text { Latent period of lesions } \\
\text { (days) }+\end{array}$} & \multirow{2}{*}{$\begin{array}{l}\text { Difference } \\
\text { between day } 0 \\
\text { and day I } \\
\text { latent } \\
\text { periods } ¥ \text { (days) }\end{array}$} \\
\hline & Day 0 & Day I & \\
\hline $\begin{array}{l}\text { No oxygenation } \\
5 \% 0 \mathrm{O}_{2} \text { in } \mathrm{N}_{2} \times 5 \mathrm{~min} \\
5 \% \mathrm{O}_{2} \text { in } \mathrm{N}_{2} \times 15 \mathrm{~min} \\
\text { Air } \times 30 \mathrm{~min} \\
\text { Air } \times 40 \mathrm{~min} \\
\text { Air } \times 50 \mathrm{~min} \\
\text { Air } \times 60 \mathrm{~min}\end{array}$ & $\begin{array}{r}10 \cdot 7 \\
9 \cdot 6 \\
10 \cdot 4 \\
9 \cdot 1 \\
9 \cdot 1 \\
12 \cdot 8 \\
12 \cdot 8\end{array}$ & $\begin{array}{l}10 \cdot 5 \\
9 \cdot 1 \\
9 \cdot 0 \\
7 \cdot 9 \\
8 \cdot 75 \\
11 \cdot 9 \\
12 \cdot 4\end{array}$ & $\begin{array}{l}-0.2 \\
-0.5 \\
-1.4 \S \\
-1.2 \\
-0.35 \\
-0.9 \\
-0.4\end{array}$ \\
\hline
\end{tabular}

*Samples for rabbit inoculation were taken from medium either immediately after additon of $T$. pallidum (day 0 ) or 24 hours later (day 1) after incubation at $34^{\circ} \mathrm{C}$

tLatent period defined as the time between rabbit inoculation and appearance of syphilitic lesion as indicated by induration in the skin. The differences in latent periods of samples taken on day 0 is due to differences in starting concentration of $T$. pallidum from different harvests and to slight differences in susceptibility of rabbits used in different experiments. In each case the data presented are the mean of 16 lesions from four rabbits. Degree of oxygenation of medium would have no effect on latent period of day 0 samples

$\neq-$ means that day 1 samples had shorter latent periods than day 0 samples

$\S$ When compared by Student's $t$ test, the difference was significant $\mathrm{P}<0.05$

When the latent periods at day 0 and 1 were compared by Student's $t$ test, the value of 1.4 days was significant at $P<0 \cdot 05$. In five repeated experiments using $5 \% \mathrm{O}_{2}$ in $\mathrm{N}_{2}$ for 15 minutes, the difference in latent period from day 0 to day 1 was always greater than for anaerobic medium, indicating better survival in the slightly oxygenated medium compared with the anaerobic medium.

Over a 48-hour incubation period in vitro, the latent period of infection always lengthened (Table 6 ), indicating a loss of virulent $T$. pallidum during this time. However the lengthening of the latent period with $5 \% \mathrm{O}_{2}$ in $\mathrm{N}_{2}$ for 15 minutes was only $4 \cdot 8$ days compared with $6 \cdot 6$ days in anaerobic medium. Differences in latent period for media with other levels of oxygenation were not significantly different to the anaerobic control.

We conclude that bubbling the anaerobic medium with $5 \%$ oxygen in nitrogen for 15 minutes (per 10-ml medium volume), resulting in a dissolved oxygen concentration of $2.4 \mu \mathrm{g} / \mathrm{l}$ (equivalent to a $3 \% \mathrm{O}_{2}$ in $\mathrm{N}_{2}$ atmosphere), significantly enhanced the survival of virulent $T$. pallidum over a 48-hour period compared with anaerobic controls. Media with
Table 6 Latent period of syphilitic lesions after inoculation of $T$. pallidum into the shaved backs of rabbits

\begin{tabular}{|c|c|c|c|}
\hline \multirow{2}{*}{$\begin{array}{l}\text { Method of } \\
\text { oxygen addition }\end{array}$} & \multicolumn{2}{|c|}{$\begin{array}{l}\text { Time at which samples } \\
\text { taken for rabbit } \\
\text { inoculation }{ }^{*}+\end{array}$} & \multirow{2}{*}{$\begin{array}{l}\text { Difference } \\
\text { between day } 0 \\
\text { and day } 2 \\
\text { latent } \\
\text { periods } \neq \text { (days) }\end{array}$} \\
\hline & Day 0 & Day 2 & \\
\hline $\begin{array}{l}\text { No oxygenation } \\
5 \% \mathrm{O}_{2} \text { in } \mathrm{N}_{2} \times 5 \mathrm{~min} \\
5 \% \mathrm{O}_{2} \text { in } \mathrm{N}_{2} \times 15 \mathrm{~min} \\
\text { Air } \times 30 \mathrm{~min} \\
\text { Air } \times 40 \mathrm{~min} \\
\text { Air } \times 60 \mathrm{~min}\end{array}$ & $\begin{array}{r}10 \cdot 1 \\
9 \cdot 6 \\
10 \cdot 4 \\
9 \cdot 0 \\
9 \cdot 0 \\
14 \cdot 5\end{array}$ & $\begin{array}{l}16 \cdot 7 \\
15 \cdot 9 \\
15 \cdot 2 \\
16 \cdot 2 \\
16 \cdot 3 \\
21 \cdot 3\end{array}$ & $\begin{array}{l}+6 \cdot 6 \\
+6 \cdot 3 \\
+4 \cdot 8 \\
+7 \cdot 2 \\
+7 \cdot 3 \\
+6 \cdot 8\end{array}$ \\
\hline
\end{tabular}

* Samples for rabbit inoculation were taken from medium either immediately after additon of $T$. pallidum (day 0 ) or $\mathbf{4 8}$ hours later (day 2) after incubation at $34^{\circ} \mathrm{C}$

tSee Table 5

$\neq+$ means that day 2 samples had longer latent periods than day 0 samples. In each experiment the day 0 and day 2 samples were inoculated into the same rabbit so as to overcome any variability between rabbits

higher concentrations of dissolved oxygen (up to $5 \cdot 8 \mu \mathrm{g} / 1$, equivalent to a $12 \cdot 6 \% \quad \mathrm{O}_{2}$ in $\mathrm{N}_{2}$ atmosphere) behaved no differently from anaerobic controls regarding retention of $T$. pallidum virulence during this time.

\section{Discussion}

From many earlier observations (Willcox and Guthe, 1966) we expected that a dissolved oxygen concentration would be detected above which oxygen was toxic to $T$. pallidum. This is because $T$. pallidum has always retained its virulence best in vitro under anaerobic conditions, implying that an atmospheric concentration of oxygen $(21 \%)$ was toxic to the bacterium. In this study, although we found an atmospheric equivalent of $3 \% \mathrm{O}_{2}$ to be the optimum concentration for the survival of virulent $T$. pallidum (Table 5), higher concentrations (up to $12 \cdot 6 \%$; Table 2) were no more detrimental to survival than anaerobic conditions. This suggests that $T$. pallidum does have inherent mechanisms for dealing with the toxic end-products of oxygen reduction (Fridovich, 1975, 1978; Haugaard, 1968), a necessary requirement for aerobic metabolism.

Oxygen at atmospheric concentrations $(21 \%)$ may, however, overwhelm these mechanisms. Since $T$. pallidum is an obligate human parasite it may have partially lost these mechanisms as a result of degenerate evolution associated with specialisation for a parasitic existence. The guanine plus cytosine $(\mathrm{G}+\mathrm{C})$ content of $T$. pallidum indicates that it may be closely related to Spirochaeta zuelzerae and Spirochaeta litoralis (Miao and Fieldsteel, 1978), free-living anaerobic spirochetes. Spirochaeta aurantia, which is a facultative anaerobe, may be a close (but non-parasitic) relative of $T$. pallidum. 
Under aerobic conditions it incompletely oxidises carbohydrates mainly to acetate and carbon dioxide. It does not possess a tricarboxylic acid (TCA) (Krebs) cycle but has developed mechanisms of oxidative phosphorylation and a rudimentary electron transport chain involving one or two cytochromes (Canale-Parola, 1977).

By comparison, $T$. pallidum degrades glucose and pyruvate to $\mathrm{CO}_{2}$ and acetate (Nichols and Baseman, 1975) under both aerobic and anaerobic.conditions, with better conversion under aerobic conditions (Baseman et al., 1976). It has a functional electron transport system probably driven by the oxidation of reduced nicotinamide-adenine dinucleotide (NADH) and reduced nicotinamide-adenine dinucleotidephosphate (NADPH) (Lysko and Cox, 1977) and coupled to oxidative phosphorylation with the production of adenosine triphosphate (ATP) (Lysko and Cox, 1978). The production of ATP in cell-free extracts was stimulated by air. The presence of catalase was also inferred by the release of $\mathrm{O}_{2}$, presumably from $\mathrm{H}_{2} \mathrm{O}_{2}$ (Lysko and Cox, 1978). Like $S$. aurantia, $T$. pallidum lacks a TCA cycle, thereby probably explaining its slow growth rate (Schiller and Cox, 1977). The most likely origin of $T$. pallidum therefore is from an ancestoral spirochete, something like Spirochaeta aurantia, capable of growing in and utilising oxygen to a limited extent. Consequently, it is not surprising that $T$. pallidum should have a requirement for an optimum oxygen concentration.

Norris et al. (1978), comparing the effect of anaerobic, aerobic, and 3\% oxygen conditions in the presence of reducing agents on the survival of virulent $T$. pallidum, found $3 \%$ oxygen to be superior.

We have come to the same conclusion after comparing anaerobic conditions and a range of dissolved oxygen concentrations in reduced culture medium. It is probably no coincidence that our determined oxygen optimum of $3 \%$ is within the range of normal rabbit tissue $(2 \cdot 6-4 \%$ oxygen; Campbell, 1931) $-1 \cdot 5 \%$ in the testis (Cross and Silver, 1962)-and human subcutaneous tissue (2.0-3.6\% oxygen; Seevers, 1936).

Using cell-free extracts, glucose and pyruvate were degraded under aerobic conditions (Nichols and Baseman, 1975). Baseman et al. (1976) found optimum substrate degradation and amino acid utilisation with 10-20\% $\mathrm{O}_{2}$. The synthesis of high molecular weight proteins and incorporation of uridine into RNA was detected under normal atmospheric conditions (Baseman and Hayes, 1977; Nichols and Baseman, 1978), incorporation being poorer with lower oxygen concentrations. However there is no evidence that atmospheric oxygen concentration is compatible with the maintenance of
T. pallidum viability as measured by the retention of virulence.

Under anaerobic, reduced conditions amino acids have been incorporated into protein (Baseman and Hayes, 1974) and serine and uracil taken up by $T$. pallidum (Sandok and Jenkin, 1978).

It appears likely that when $T$. pallidum is successfully grown in vitro, it will grow in quite a wide range of oxygen concentrations, but from our present state of knowledge studies on the in-vitro growth of this bacterium should be conducted under microaerophilic conditions.

It is interesting that a human malaria protozoon (Plasmodium falciparum), another human parasite which defied cultivation in vitro for many years, has recently been grown in a culture system with $1 \%$ or $5 \%$ oxygen (Trager and Jensen, 1976).

We wish to thank Mr Ian McLean for his excellent technical assistance and Dr J. Watterson of Monash University, Department of Mathematics, for valuable help with the statistical analysis.

This work was supported by grants from the National Health and Medical Research Council, the Utah Foundation, the Danks Trust, the estate of the. late George Adams, the Ian Potter Foundation, and Monash University, from whom funds are gratefully acknowledged.

\section{References}

Baseman, J. and Hayes, N. (1974). Protein synthesis by Treponema pallidum extracted from infected rabbit tissue. Infection and Immunity, 10, 1350-1355.

Baseman, J. and Hayes, N. (1977). Anabolic potential of virulent Treponema pallidum. Infection and Immunity, 18, 857-859.

Baseman, J., Nichols, J., and Hayes, N. (1976). Virulent Treponema pallidum: aerobe or anaerobe. Infection and Immunity, 13, 704-711.

Campbell, J. (1931). Gas tensions in tissues. Physiology Review, 11, $1-40$

Canale-Parola, E. (1977). Physiology and evolution of spirochaetes Bacteriology Review, 41, 181-204

Cox, C. and Barber, M. (1974). Oxygen uptake by Treponema pallidum. Infection and Immunity, 10, 123-127.

Cross, B. and Silver, I. (1962). Neurovascular control of oxygen tension in the testis and epididymis. Journal of Reproduction and Fertility, 3, 377-395.

Fieldsteel, A., Becker, F., and Stout, J. (1977). Prolonged survival of virulent Treponema pallidum (Nichols strain) in cell free and tissue culture systems. Infection and Immunity, 18, 173-182.

Fitzgerald, T., Johnson, R., Sykes, J., and Miller, J. (1977). Interaction of Treponema pallidum (Nichols strain) with cultured mammalian cells: effect of oxygen, reducing agents, serum supplements and different cell lines. Infection and Immunity, 15, 444-452.

Fitzgerald, T., Johnson, R., and Wolff, E. (1978). Mucopolysaccharide material resulting from the interaction of Treponema pallidum (Nichols strain) with cultured mammalian cells. Infection and Immunity, 22, 575-584.

Fitzgerald, T., Miller, J., and Sykes, J. (1975). Treponema pallidum (Nichols strain) in tissue cultures: cellular attachment, entry, and survival. Infection and Immunity, 11, 1133-1140.

Fridovich, I. (1975). Oxygen: boon and bane. American Scientist, 63, 54-59.

Fridovich, 1. (1978). The biology of oxygen radicals. Science, 201, 875-880. 
Graves, S., Sandok, P., Jenkin, H., and Johnson, R. (1975). Retention of motility and virulence of Treponema pallidum (Nichols strain) in vitro. Infection and Immunity, 12, 1116-1120.

Haugaard, N. (1968). Cellular mechanism of oxygen toxicity. Physiology Review, 48, 311-373.

Jacob, H. E. (1970). Redox potential. In Methods in Microbiology, volume 2 . Edited by J. Norris and D. Ribbons. Academic Press.

Kiraly, K. and Horvath, I. (1976). Survival of T. pallidum under microaerobic conditions in cell and tissue cultures. Zentralblatt für Bakteriologie, Parasitenkunde, Infections-Krankheiten und Hygiene, I Abt. Orig. A., 235, 500-505.

Lysko, P. and Cox, C. (1977). Terminal electron transport in Treponema pallidum. Infection and Immunity, 16, 885-890.

Lysko, P. and Cox, C. (1978). Respiration and oxidative phosphorylation in Treponema pallidum. Infection and Immunity, 21, 462-473.

Metzger, M. and Smogor, W. (1966). Study of the effect of pH and Eh values of the Nelsen-Diesendruck medium on the survival of virulent Treponema pallidum. Archivum Immunologiae et Therapiae Experimentalis, 14, 445-453.

Miao, R and Fieldsteel, A. (1978). Genetics of Treponema: Relationship between Treponema pallidum and five cultivable treponemes. Journal of Bacteriology, 133, 101-113.

Nichols, J. and Baseman, J. (1975). Carbon sources utilised by virulent Treponema pallidum. Infection and Immunity, 12, 1044-1050.

Nichols, J. and Baseman, J. (1978). Ribosomal ribonucleic acid synthesis by virulent Treponema pallidum. Infection and Immunity, 19, 854-860.
Norris, S., Miller, J., Sykes, J., and Fitzgerald, T. (1978). Influence of oxygen tension, sulfhydryl compounds, and serum on the motility and virulence of Treponema pallidum (Nichols strain) in a cell-free system. Infection and Immunity, 22, 689-697.

Sandok, P., and Jenkin, H. (1978). Radiolabelling of Treponema pallidum (Nichols virulent strain) in vitro with precursors for protein and RNA biosynthesis. Infection and Immunity, 22, 22-28.

Sandok, P., Jenkin, H., Matthews, H., and Roberts, M. (1978). Unsustained multiplication of Treponema pallidum (Nichols virulent strain) in vitro in the presence of oxygen. Infection and Immunity, 19, 421-429.

Sandok, P., Knight, S., and Jenkin, H. (1976). Examination of various cell culture techniques for co-incubation of virulent Treponema pallidum (Nichols I strain) under anaerobic conditions. Journal of Clinical Microbiology, 4, 360-371.

Schiller, N. and Cox, C. (1977). Catabilism of glucose and fatty acids by virulent Treponema pallidum. Infection and Immunity, 16, 60-68.

Seevers, M. (1936). $\mathrm{O}_{2}$ and $\mathrm{CO}_{2}$ tensions in the subcutaneous tissues of normal subjects. American Journal of Physiology, 115, 38-42.

Trager, W. and Jensen, J. (1976). Human malaria parasites in continuous culture. Science, 193, 673-725.

Willcox, R. and Guthe, T. (1966). Treponema pallidum: A bibliographical review of the morphology, culture and survival of $T$. pallidum and associated organisms. Bulletin of the World Health Organisation, vol. 35 suppl. WHO: Geneva. 